\title{
Foreword
}

\section{The 8th International Conference on Biomedical Engineering and Biotechnology}

\author{
Severin P. Schwarzacher ${ }^{\mathrm{a}, *}$ and Carlos Gómez ${ }^{\mathrm{b}}$

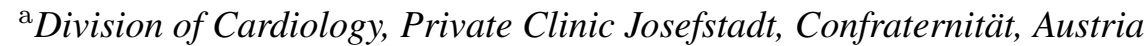 \\ ${ }^{\mathrm{b}}$ Biomedical Engineering Group, University of Valladolid, Valladolid, Spain
}

I am delighted to welcome you to the Supplement Issue of the Technology and Health Care Journal which offers you papers covering a thrilling and wide range of topics.

In the clinical environment still today many clinicians believe to see a separation between clinical medicine and biotechnology, and the mutual connection of those is sometimes hardly appreciated. Thus, I want to emphasize the crucial importance of biotechnological research for the development of diagnostic and therapeutical tools then applied and translated into daily clinical routine. In fact, many new diagnostic tools as well as therapeutic approaches to patients would not have been possible without biotechnological research as presented in this very supplement.

The researchers from all around the globe who contributed to this supplement put a lot of energy and effort into the research, some of which will support in helping patients around the world with new ways of treatment and technology. I take great pleasure to thank them for their valuable contributions.

We would also like to express our sincere appreciation to the Technical Program Committee members as well as the reviewers who have provided us with their professional guidance and advice to the conference to make it a success.

We also want to highlight the upcoming conference iCBEB 2020, which will be held during November 15-18, in Suzhou, China. We truly hope to see you there.

\footnotetext{
${ }^{*}$ Corresponding author: Severin P. Schwarzacher, Division of Cardiology, Private Clinic Josefstadt, Confraternität, Austria. E-mail: severin.schwarzacher@aon.at.

0928-7329/20/\$35.00 (c) 2020 - IOS Press and the authors. All rights reserved

This article is published online with Open Access and distributed under the terms of the Creative Commons Attribution Non-Commercial License (CC BY-NC 4.0).
} 